\title{
A RETROSPECTIVE STUDY TO DETERMINE THE CASES OF MALARIA AT RAIGARH DISTRICT, CHHATTISGARH- AN OBSERVATIONAL ANALYSIS
}

\section{Chawda Hanish $\mathrm{K}^{1}$, Naik Reena ${ }^{2 *}$, Minj Manoj $\mathrm{K}^{3}$, Bharadwaj Amit $\mathrm{K}^{4}$}

${ }^{1} \mathrm{MD}$, Pathology, Assistant Professor in Pathology, Govt. Medical College, (LSLAMMC), Raigarh, Chhattisgarh.

${ }^{2}$ MBBS, DNB, Pathology, Assistant Professor in Pathology, Govt. Medical College, (LSLAMMC), Raigarh, Chhattisgarh.

${ }^{3} \mathrm{MD}$, Pathology, Prof \& HOD, Dept of Pathology, Govt. Medical College, (LSLAMMC), Raigarh, Chhattisgarh.

${ }^{4} \mathrm{MD}$ (Pathology), Assistant Professor in Pathology, Govt. Medical College, (LSLAMMC), Raigarh, Chhattisgarh.

Article Info: Received 10 February 2019; Accepted 12 March. 2019

Cite this article as: K, C., Reena, N., K, M., \& K, B. (2019). A RETROSPECTIVE STUDY TO DETERMINE THE CASES OF MALARIA AT RAIGARH DISTRICT, CHHATTISGARH- AN OBSERVATIONAL ANALYSIS. International Journal of Medical and Biomedical Studies, 3(3).

DOI: https://doi.org/10.32553/ijmbs.v3i3.135

Address for Correspondence: Dr. Reena Naik, Assistant Professor, Dept of Pathology, Govt. Medical College, Raigarh, Chhattisgarh

Conflict of interest: No conflict of interest.

\section{Abstract}

Background: Malaria remains the most important disease responsible for causing great suffering and loss of life in the world. The rationale behind the present study was to determine the proportion of Malaria and compare the record data.

Objectives: To determine the prevalence of Malaria and to compare the prevalence sex wise, age wise and to investigate which species is prevalent in Raigarh.

Material \& Methods: Retrospective record-based study was done were the data from January 2009 to December 2018 was gathered and analyzed. Prevalence was calculated and Epi-info (7.0) software was used.

Results: 79218 blood smears prepared in 10 years in which 2911 smear were positive which indicates around $3.67 \%$ cases were positive. The Prevalence rate is falling with increasing years which indicates the importance of Malaria eradication programme. Positive cases were found to be highest under 10 years (46.58\%). Male preponderance and Plasmodium falciparum is the most common species.

Conclusion: Health education through IEC (Information, Education and Communication) activities and behavioural change communication (BCC) are very important intervention measures aimed at improvement of environmental sanitation and personal protection from mosquito bites for the elimination of malaria in the endemic areas as well as in the whole country.

Keywords: Malaria, prevalence, plasmodium falciparum 


\section{INTRODUCTION:}

Malaria remains the most important disease responsible for causing great suffering and loss of life in the world. Details of this disease can be found even in the ancient Indian medical literature like the Atharva Veda and Charaka Samhita. At present, official figures for malaria in India, available at NVBDCP ${ }^{1}$ indicate 0.7-1.6 million confirmed cases and 400-1,000 deaths annually. ${ }^{2}$ The biggest burden of malaria in India is borne by the most backward, poor and remote parts of the country, with $>90-95 \%$ cases reported from rural areas and $<5-10 \%$ from urban areas. Incidence of Malaria in India total cases 1.07 million, plasmodium falciparum 70 million. The common symptoms are high fevers and chills in human beings. The parasite is transmitted from an infected person to the other person, by the bites of certain female Anapheles mosquitoes which feed on the red blood cells at night. The World Health Organization reported 219 million cases of malaria with an estimated 660,000 deaths. South East Asia is the second most affected region in the world after Africa, and India has the highest (61\%) malaria burden in the region with an estimated 24 million cases per year. Plasmodium falciparum malaria continues to be a major public health threat in India, with nearly half (273 million) of the highrisk population outside Africa residing in India ${ }^{1}$. India contributes over one fifth $(22.6 \%)$ of clinical episodes of P. falciparum globally. ${ }^{2}$ The NVBDCP Epidemiological report of 2013-14 was also reported the prevalence of $\mathrm{P}$. falciparum infection in Andhra Pradesh as 68.85\% in 2013 and $74.60 \%$ by September 2014, while the corresponding figures for the neighboring state of Chhattisgarh were $78.80 \%$ and $84.26 \%$, respectively ${ }^{3}$. One of the reasons attributed to the rise in proportion of $P$. falciparum cases is resistance to chloroquine, which was used for a long time as the first line of treatment in malaria cases ${ }^{4}$. So, this study was planned to determine the proportion of malaria cases in both rural and urban area of Raigarh.

\section{Materials \& Methods}

Study Area- District Hospital, Raigarh

Study Design- Retrospective study

Study Population- Peripheral Smears of suspected Cases

Study duration- data from January 2009 to December 2018 (10 years) was gathered.

Sampling Technique- Purposive sampling technique

Sample size- A total of 79218 blood smears was studied.

Methodology- All the samples which were subjected to laboratory were included in the study.

Consent Type- Informed consent

Ethical Approval- Study was approved by Institutional Ethical Committee.

Statistical Analysis- Data will be consolidated and entered a Microsoft Excel spreadsheet and then transferred to Epi info version (7.1.3.0. centre for disease control and prevention, Atlanta, Georgia, USA, 2013) software for analysis. The prevalence was determined in the form of percentages (\%).

\section{RESULT}

Table 1: Year wise Prevalence of Malaria in the study area

\begin{tabular}{|l|l|l|l|}
\hline Year & Collection & Positive & $\begin{array}{l}\text { Prevalence } \\
\text { (\%) }\end{array}$ \\
\hline $\mathbf{2 0 0 9}$ & 13747 & 663 & 4.82 \\
\hline $\mathbf{2 0 1 0}$ & 11616 & 763 & 6.57 \\
\hline $\mathbf{2 0 1 1}$ & 8573 & 334 & 3.90 \\
\hline $\mathbf{2 0 1 2}$ & 6860 & 232 & 3.38 \\
\hline $\mathbf{2 0 1 3}$ & 7326 & 189 & 2.58 \\
\hline $\mathbf{2 0 1 4}$ & 8706 & 244 & 2.80 \\
\hline $\mathbf{2 0 1 5}$ & 8237 & 249 & 3.02 \\
\hline $\mathbf{2 0 1 6}$ & 4877 & 85 & 1.74 \\
\hline $\mathbf{2 0 1 7}$ & 4243 & 89 & 2.10 \\
\hline $\mathbf{2 0 1 8}$ & 5033 & 63 & 1.25 \\
\hline
\end{tabular}

As per table 1 total of 79218 blood smears prepared in 10 years (Jan 2009 - Dec2018) from that 2911 smear were positive which indicates around $3.67 \%$ cases were positive. As seen the Prevalence rate is falling with increasing years which indicates the level of treatment (fig 1), in 
2009 it is $4.82 \%$ and 2018 it is 1.2

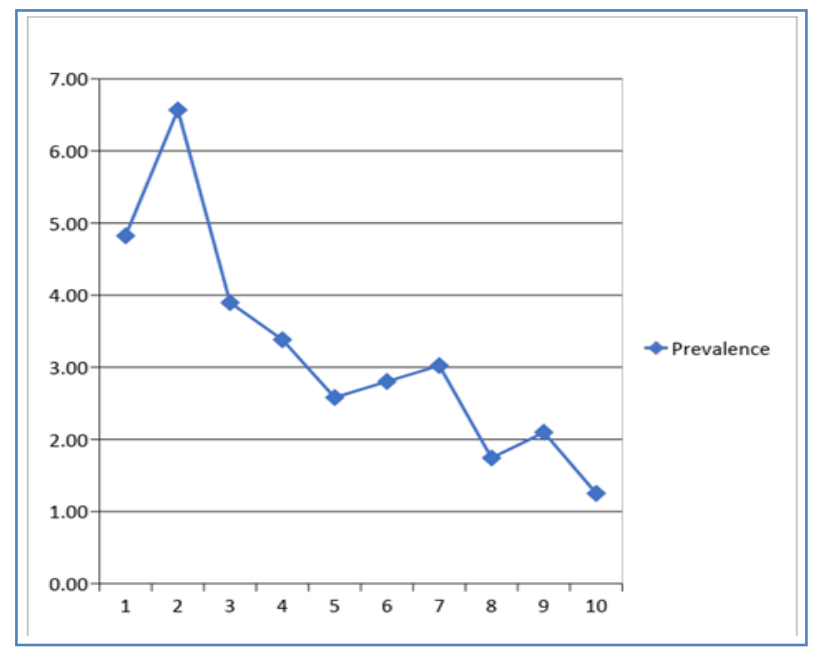

Figure 1 shows the Prevalence of Malaria

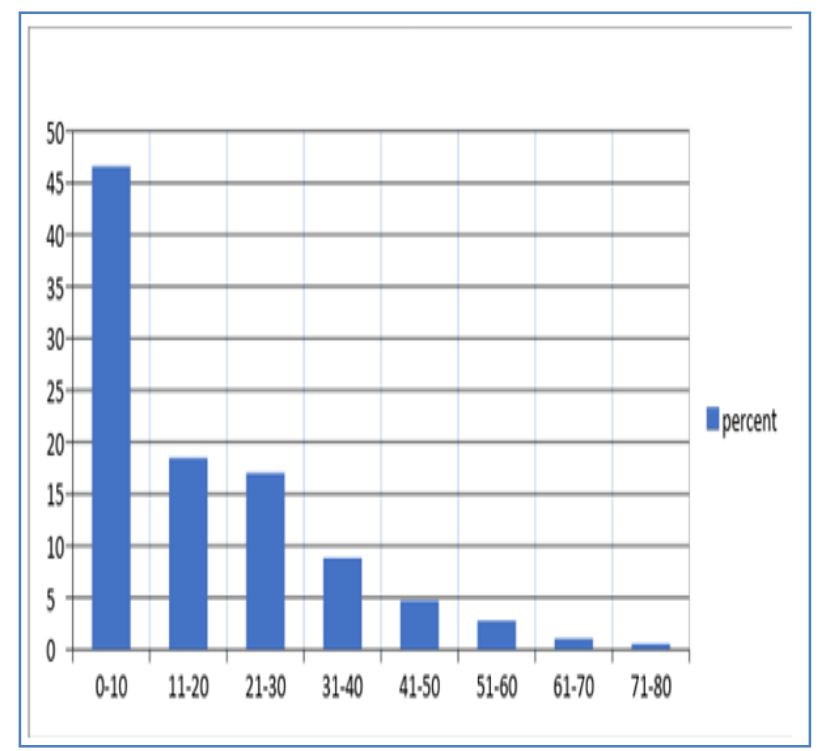

Figure 2: Age wise distribution of cases of Malaria

Table 2: Age wise distribution of cases

\begin{tabular}{|l|l|l|l|l|l|l|l|l|}
\hline Year & $\mathbf{0 - 1 0}$ & $\mathbf{1 1 - 2 0}$ & $\mathbf{2 1 - 3 0}$ & $\mathbf{3 1 - 4 0}$ & $\mathbf{4 1 - 5 0}$ & $\mathbf{5 1 - 6 0}$ & $\mathbf{6 1 - 7 0}$ & $\mathbf{7 1 - 8 0}$ \\
\hline $\mathbf{2 0 0 9}$ & 303 & 149 & 101 & 59 & 23 & 18 & 5 & 5 \\
\hline $\mathbf{2 0 1 0}$ & 335 & 162 & 132 & 67 & 30 & 25 & 8 & 4 \\
\hline $\mathbf{2 0 1 1}$ & 146 & 53 & 48 & 38 & 25 & 12 & 9 & 3 \\
\hline $\mathbf{2 0 1 2}$ & 134 & 29 & 37 & 15 & 12 & 4 & 0 & 1 \\
\hline $\mathbf{2 0 1 3}$ & 109 & 29 & 30 & 12 & 4 & 4 & 0 & 1 \\
\hline $\mathbf{2 0 1 4}$ & 137 & 28 & 43 & 14 & 16 & 6 & 0 & 0 \\
\hline $\mathbf{2 0 1 5}$ & 105 & 34 & 55 & 28 & 16 & 5 & 6 & 0 \\
\hline $\mathbf{2 0 1 6}$ & 34 & 15 & 15 & 12 & 5 & 1 & 2 & 1 \\
\hline $\mathbf{2 0 1 7}$ & 35 & 24 & 19 & 5 & 1 & 4 & 0 & 1 \\
\hline $\mathbf{2 0 1 8}$ & 18 & 14 & 15 & 7 & 6 & 2 & 1 & 0 \\
\hline Total case & 1356 & 537 & 495 & 257 & 138 & 81 & 31 & 16 \\
\hline percentage & 46.58 & 18.45 & 17.00 & 8.83 & 4.74 & 2.78 & 1.06 & 0.55 \\
\hline
\end{tabular}

As per Figure 2 and Table 2 Cases includes all age groups and were classified into various age group, positive cases were found to be highest under 10 years $(46.58 \%)$ and minimum in $(71-80 \mathrm{yr})$ is $0.55 \%$. which is in decreasing trends with increasing age. 
Table 3: Sex wise Comparison Malaria cases in terms of prevalence.

\begin{tabular}{|l|l|l|l|l|l|}
\hline Year & Positive & Male & $\begin{array}{l}\text { Male } \\
\text { Prevalence (\%) }\end{array}$ & Female & $\begin{array}{l}\text { Female } \\
\text { Prevalence (\%) }\end{array}$ \\
\hline $\mathbf{2 0 0 9}$ & 663 & 342 & 51.58 & 321 & 48.42 \\
\hline $\mathbf{2 0 1 0}$ & 763 & 398 & 52.16 & 365 & 47.84 \\
\hline $\mathbf{2 0 1 1}$ & 334 & 168 & 50.30 & 166 & 49.70 \\
\hline $\mathbf{2 0 1 2}$ & 232 & 121 & 52.16 & 111 & 47.84 \\
\hline $\mathbf{2 0 1 3}$ & 189 & 99 & 52.38 & 90 & 47.62 \\
\hline $\mathbf{2 0 1 4}$ & 244 & 137 & 56.15 & 107 & 43.85 \\
\hline $\mathbf{2 0 1 5}$ & 249 & 126 & 50.60 & 123 & 49.40 \\
\hline $\mathbf{2 0 1 6}$ & 85 & 50 & 58.82 & 35 & 41.18 \\
\hline $\mathbf{2 0 1 7}$ & 89 & 51 & 57.30 & 38 & 42.70 \\
\hline $\mathbf{2 0 1 8}$ & 63 & 41 & 65.08 & 22 & 34.92 \\
\hline Total case and percentage. & 2911 & 1533 & 52.66 & 1378 & 47.34 \\
\hline
\end{tabular}

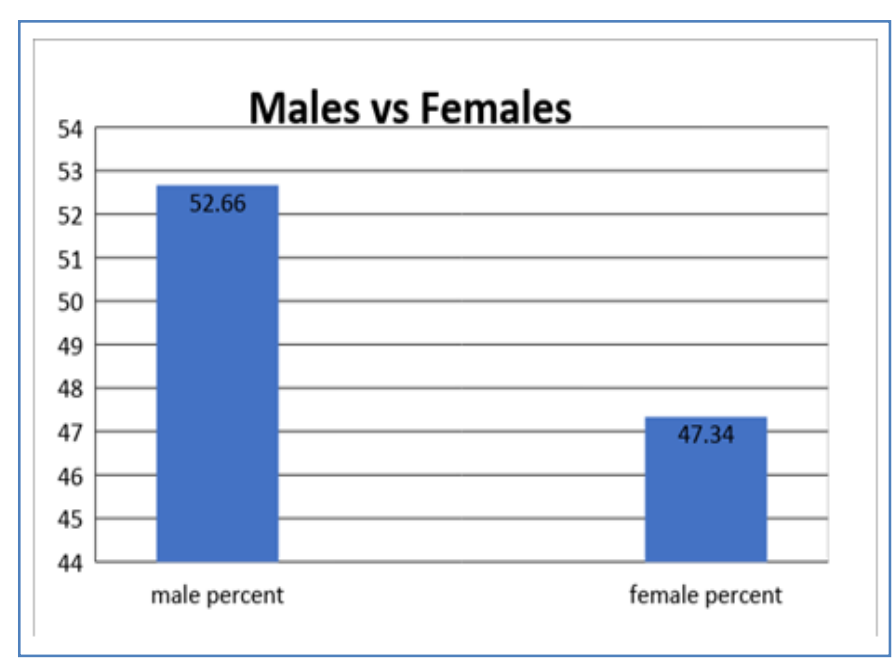

Figure 3: Sex wise comparison of cases

As per table 3 the study is male preponderance as the males comprises (53\%) of malaria cases while female only $47 \%$.

Table 4: Comparison of cases in terms of Plasmodium Vivax and Plasmodium Falciparum

\begin{tabular}{|l|l|l|l|l|l|}
\hline Year & Positive & PV & PV prevalence & PF & PF prevalence \\
\hline 2009 & 663 & 197 & 29.71 & 466 & 70.29 \\
\hline 2010 & 763 & 161 & 21.10 & 602 & 78.90 \\
\hline 2011 & 334 & 71 & 21.26 & 263 & 78.74 \\
\hline 2012 & 232 & 57 & 24.57 & 175 & 75.43 \\
\hline 2013 & 189 & 29 & 15.34 & 160 & 84.66 \\
\hline 2014 & 244 & 48 & 19.67 & 196 & 80.33 \\
\hline 2015 & 249 & 53 & 21.29 & 196 & 78.71 \\
\hline 2016 & 85 & 31 & 36.47 & 54 & 63.53 \\
\hline 2017 & 89 & 26 & 29.21 & 63 & 70.79 \\
\hline 2018 & 63 & 17 & 26.98 & 46 & 73.02 \\
\hline Total & 2911 & 690 & 23.70 & 2221 & 76.30 \\
\hline
\end{tabular}


As per table 4 we further classified according to species and we found only two species were plasmodium falciparum and plasmodium vivax. Majority includes falciparum cases $(76.3 \%)$ in comparison to vivax $(23.70 \%)$ it is three fourth of all positive cases. Trend is maintained in every year.

\section{Discussion and Conclusion-}

The epidemiology of malaria is the product of complex interaction between host vector and parasite factor that are specific to each location in which malaria occurs. ${ }^{5}$ Malaria in central India (Chhattisgarh) is complex because of the vast tracts of forest with tribal settlement. Furthermore, socioeconomic status, cultural characteristic, health care infrastructure, and degree of mobility of population also differ between locations and populations, and contribute to the diversity of malaria characteristics in the region. In our study we found decreasing trends of malaria over passing years. Cause for this may be due to malaria control programme in India like national malaria control programme (NMCP) 1953, national malaria eradication programme (NMEP) 1958, multipurpose worker scheme (MPW scheme) 1979 and implementation of malaria action plan 1995 (MAP-95). All these plans were very effective that change our goal from control to eradication. On the other hand, factors related to the human population could also be relevant, such as levels of acquired immunity and levels of self-protection including self-medication and awareness. In our study we found that prevalence is more in paediatric age group and highest approximately half cases were under $10 \mathrm{yr}$ age group, severe malaria most commonly occurs in young children. ${ }^{6}$ Where malaria transmission is low or unstable (sporadic or periodic) as has been described in southeast Asia, natural immunity is slow to develop, all age groups are affected. ${ }^{7,8}$ In this study we found that positive cases were more prevalent in male than female, possibly due to male person were out of home for service, Raigarh is industrial area where continuous construction work in progress and lot of garbage surrounding that area, as well as nearby forest area and rural agricultural fields where mainly male workers are doing work. In our study we found that burden of falciparum cases are more than vivax. Which is like the World Malaria Report 2014. ${ }^{4}$ In 2013, 0.88 million cases have been recorded, with 128 million tests being conducted on the suspected cases, with $P$. falciparum causing $53 \%$ and $P$. vivax causing $47 \%$ of the infections. One study conducted in Bilaspur Chhattisgarh in 2006, they also found more prevalence of falciparum that is $76.1 \% .^{9}$ in the proportion of p. falciparum infection over p.vivax may be because of prevailing chloroquine resistance against $p$. falciparum which is existing in the area since $1980 .^{10}$

Since unbridled urbanization, drought, migration of worker and lack of awareness about preventive measures are all contributing to resurgence of malaria in India and outbreaks are frequently recorded. C.G. is rural agricultural state marked by severe poverty and underdevelopment. So, it is logistically very difficult to control malaria in India and the problem is expected to exacerbate in the coming years. It is also important that the community needs to be involved through inclusion of grass root health workers such as Accredited social health activists (ASHAs) and community health workers $^{9}$ Health education through IEC (Information, Education and Communication) activities and behavioural change communication (BCC) are also very important intervention measures aimed at improvement of environmental sanitation and personal protection from mosquito bites for the elimination of malaria in the endemic areas as well as in the whole country.

\section{References-}

1. Malaria situation. National Vector Borne Disease control Programme. Available at http://nvbdcp.gov.in/Doc/mal_situation_Jan 2015.pdf 
2. Ashwani Kumar, Neena Valecha, Tanu Jain, Aditya P. Dash. Burden of Malaria in India: Retrospective and Prospective View. Am J Trop Med Hyg. 2007;77:69-78.

3. NVBDCP. National Vector Borne Disease Control Programme. 22, Shamath Marg, New Delhi.

4. WHO: World Malaria Report. Geneva, Switzerland: World Health Organization (WHO). 2012

5. Bruce-Chwatt LJ, 1987. Malaria and its control: present situation and future prospects. Annu Rev Public Health 8: 75110.

6. Molineaux L, Gramiccia G, 1980. The Garki Project, Research on the Epidemiology and Control of Malaria in the Sudan Savanna of West Africa. Geneva: World Health Organization.
7. Theander TG, 1998. Unstable malaria in Sudan. The influence of the dry season. Trans R Soc Trop Med Hyg 92.

8. Luxemburger $\mathrm{C}$, Thwai KL, White NJ, Webster HK, Kyle DE, Maelankirn L, Chongsuphajaisiddhi T, Nosten F, 1996. The epidemiology of malaria in a Karen population on the western border of Thailand. Trans R Soc Trop Med Hyg 90: 105-111.

9. Hussain MA, Dandona L, Schellenberg D: Public health system readiness to treat malaria in Odisha State of India. Malar J. 2013; 12: 351.

10. Hay SI, Okiro EA, Gething PW, et al.: Estimating the global clinical burden of Plasmodium falciparum malaria in 2007. PLoS Med. 2010; 7(6): e1000290. 